\title{
Warmth and Competence: A Content Analysis of Photographs Depicting American Presidents
}

\author{
Eric Hehman, Elana C. Graber, Lindsay H. Hoffman, and Samuel L. Gaertner \\ University of Delaware
}

\begin{abstract}
The current research examines whether images presented alongside online articles might systematically vary in how political targets are presented. We focus our analyses on how presidents who either share or do not share political orientations with Internet media outlets are portrayed along the dimensions of warmth and competence, qualities highly prized in leadership and effectively conveyed in facial images. Four hundred twenty-two images from five online media outlets were coded for warmth and competence. Media outlets sharing political orientations with a target portrayed them as more warm and competent than targets of another orientation. The viability of this effect as a potential mechanism to influence readers of online articles is discussed.
\end{abstract}

Keywords: content analysis, image analysis, framing

As print readership has markedly declined, news organizations are increasingly embracing the Internet as an outlet for publication and promotion primarily due to the increased number of people seeking news online (Purcell, Rainie, Mitchell, Rosenstiel, \& Olmstead, 2010). Differences in printed, televised, and Internet news media (e.g., design, financial, and space issues, etc.) lead to presenting a single story in multiple ways (Craig, 1999; Messaris \& Abraham, 2003), which may have varying effects upon an audience. Researchers have accordingly redirected their attention to Internet outlets to assess the impact Internet media may have on audiences (e.g., Hoffman, 2006; Lee, 2007). Given the abundance of images accompanying online media content, the present study examines the viability of one mechanism, image presentation, to influence the impressions readers may form of political figures. We focus on two independent dimensions important in impression formation and leadership evaluation: warmth and competence.

Eric Hehman, Elana C. Graber and Samuel L. Gaertner, Department of Psychology, University of Delaware; Lindsay H. Hoffman, Department of Communication, University of Delaware.

Correspondence concerning this article should be addressed to Eric Hehman, Department of Psychology, 108 Wolf Hall, University of Delaware, Newark, DE 19716. E-mail: ehehman@udel.edu

\section{Image Influence}

Images attract attention and retain audiences. When given a limited time to choose between reading several articles with or without images, participants select and spend the most time reading articles accompanied by photographs (Zillman, Knobloch, \& Yu, 2001). Pictures also contribute to the emotional involvement of the reader in the article. For instance, participants included ethical considerations in their decisions regarding moral dilemmas more so after reading articles with pictures, as compared with those who read the same article without photos (Coleman, 2006). Similarly, participants viewing images of combat operations in Iraq, as compared to reading reports of combat operations, showed increased involvement in the war and reduced support for a continued military presence (Pfau et al., 2008).

Photographs additionally impact how information in articles is attended to and recalled. Exposure to articles with accompanying images resulted in readers spending more time on portions of the article where the images were presented (Sargent, 2007). Regarding recall, the inclusion of images alongside text increases the memorability of the message (Katz, Adoni, \& Parness, 1977), particularly when the images match the tone and content of the story (Walma van der Molen \& Klijn, 2004). It is clear that presenting images alongside articles can influence how an article is perceived. Thus, in an 
online news environment where readers are exposed to an increasing number of images, it is important to assess how the images presented may influence the readers prior to their evaluations of content.

\section{Image Influences on Target Evaluations}

Content analyses of media outlets have largely focused on textual content, prompting calls for increased analysis of accompanying imagery (Graber, 1989, 1996). Such a focus is important, as photographic images can influence audience perceptions more subtly than written content, exemplified by the effects of target perceptions of voters on voting outcomes. For instance, when photos of Barack Obama were manipulated such that he appeared darker or lighter in skin color, the extent to which people rated the lightened photographs as representative of him was related to their voting behavior in the 2008 presidential election (Caruso, Mead, \& Balcetis, 2009).

The current research focuses on the manner in which political figures are presented, specifically recent U.S. presidents, to investigate the viability of image presentation as a mechanism through which readers might be subtly influenced. How might the portrayal of a president influence reader impressions? Research reveals that an immense amount of information is conveyed by a face. Observers viewing people's faces can accurately guess subtle factors such as upper body strength (Sell et al., 2009), sexual orientation (Rule, Ambady, Adams, \& Macrae, 2008), or even political affiliation (Rule \& Ambady, 2010). These evaluations can predict serious "real-world" outcomes. For example, evaluations of Chief Executive Officers' faces by naïve coders predict their companies' profits (Rule \& Ambady, 2008), and judgments of political candidate's faces can predict their likelihood of election (Antonakis \& Dalgas, 2009; Poutvaara, Jordahl, \& Berggren, 2009). Two primary factors conveyed by the face are related to desired qualities in leadership and thus political success: warmth and competence (Funk, 1997; Todorov, Mandisodza, Goren, \& Hall, 2005). These factors have successfully predicted electoral success both in the United States and in other cultures, reflecting the universal desirability of these qualities for leadership.

Previous studies have only analyzed varying amounts of warmth and competence expressed in the faces of different political figures using single images of each person. However, different images of the same target may additionally vary in the degree of warmth and competence depicted. Media outlets have vast databases of images to accompany news articles, and thus these images vary in how warmly or competently a target is portrayed. We hypothesize that a media outlet's political ideology is correlated with the degree of warmth and competence depicted in the presented images of political figures, which will vary with the degree of support for each figure.

Images accompanying articles may actually be more effective at influencing public opinion than "statement" bias, favorable coverage of one party over another, or "gatekeeping" bias, selecting stories from one party over another (D'Allessio \& Allen, 2000). Indeed, the media play a major role in making certain traits of candidates more salient or prominent than others (Weaver, 1981). The amount of emphasis certain characteristics receive is strongly related to the importance attributed to these characteristics (Iyengar \& Kinder, 1987; Scheufele \& Tewksbury, 2007). While research suggests that the media exert limited influence on what their audience believes about a certain issue (Weaver, 1996), they do play a large role in influencing the impressions people form regarding political figures' personality characteristics (McCombs \& Shaw, 1972), additionally important in influencing a political figure's electoral success. A mechanism through which this impact might occur is image presentation. As individuals utilize the Internet to search for political information (Brubaker, 2010; Johnson, Kaye, Bichard, \& Wong, 2007; Kaye \& Johnson, 2002) the presentation of political figures varying in warmth and competence may influence the impressions formed, or polarize those already formed (Coe et al., 2008), during this process.

Building on the above logic, we focus our analysis on the two most recent American presidents, Barack Obama and George W. Bush, for several reasons. First, as members of opposing political parties, we expected variation in how media outlets that are generally perceived to be either conservative or liberal (Pew Research Center, 2009) would portray each target. A second reason for choosing these targets is that our content analysis is specifically interested in Internet news articles due to the abundance of images accompanying the written content. As 
media organizations have shifted their resources to online content only in the past decade, images of presidents from before this time were not available in numbers sufficient for analysis. ${ }^{1}$ It is important to assess whether the presentation of more warm or competent images is a way in which the sources of news information might influence reader perceptions of a political figure, and this possibility would be supported if media outlets portrayed political figures sharing their political orientation as both warmer and more competent than those holding other political orientations.

Thus, images from Internet media outlets sharing a target's political orientation will be rated as portraying the target as warmer $(\mathrm{H} 1)$ and more competent $(\mathrm{H} 2)$ than those that do not share the target's political orientation.

\section{Method}

\section{Sample}

Images were collected during May, 2010 of each target during times of their presidency (i.e., 1/20/2001-1/19/2009 for George W. Bush; 1/20/2009-5/15/2010 for Barack Obama). Five media outlets were selected as sources of images based upon wide readership, clear classification as conservative- or liberal-leaning, and an availability of images accompanying online articles. We selected both traditional news media outlets and well-known blogs. Images were selected from outlets favored by conservatives: FOX.com $(n=102)$ and Townhall $(n=104$; Iyengar \& Hahn, 2009), as well as outlets favored by liberals: CNN.com $(n=78)$, MSNBC .com $(n=87)$, and the Huffington Post $(n=93$; Iyengar \& Hahn, 2009). Fourteen research assistants blind to the hypotheses were instructed to collect approximately 50 images of an assigned target from an assigned website published during the times described above. Images were collected by searching for news articles about each target on the media outlet's website, and selected only if they had been posted alongside a news article published during the target's presidency (see Figure 1).

Following collection, images were excluded if they portrayed a target with another (future or former) president; occluded more than half of a target's face (i.e., the target was facing away from the camera, or the face was cut off by the frame of the image); were thumbnails for a video or slideshow embedded in an article; were reproductions of an image (e.g., an individual wearing an Obama t-shirt); or were images where the target was not a main focus. Multiple identical images from a single outlet were eliminated, though images were coded multiple times provided the outlet source of the image varied (i.e., the same image appearing in both a FOX.com and CNN.com article). Following exclusionary criteria, the final sample consisted of: FOX.com (Bush $n=45$; Obama $n=52$ ), Townhall (Bush $n=45$; Obama $n=35$ ), CNN .com (Bush $n=17$; Obama $n=53$ ), MSNBC .com (Bush $n=45$; Obama $n=35$ ), and Huffington Post (Bush $n=29$; Obama $n=46$ ) for a total $N$ of 422 .

\section{Coding}

A total of six research assistants, uninvolved in image collection and blind to both the hypotheses and source of the images, were involved in the coding of the images. Each image was coded by three of the research assistants. Coders received written instructions to evaluate each political leader depicted within the images on the following four features: competence, dominance (i.e., the competence dimension), likability, and trustworthiness (i.e., the warmth dimension). These items have successfully captured these dimensions previously in related research (Rule \& Ambady, 2008; Rule et al., 2010). All images were coded for the extent to which the leader displayed each of these qualities, using a scale of 1 (Not at all) to 7 (Very much). We capitalized on the coders' intuitive expertise in capturing social phenomena, allowing them to use their own definitions for each of the measured constructs. This use of "naïve" coders has also been advocated for in the literature, particularly when subjective evaluations are the construct of interest as in the current research (Schulz \& Waldinger, 2005). Naïve ratings have successfully predicted objective outcomes such as electoral success (Rule et al., 2010; Todorov et al., 2005) or company profits (Rule \& Ambady, 2008) across multiple studies and do-

\footnotetext{
${ }^{1}$ Thirty-eight images of Bill Clinton were collected from CNN.com. These images were not included in the reported analysis, as images of Clinton from any other outlet were unavailable in sizeable quantities. Including these images in analyses does not substantively alter results.
} 

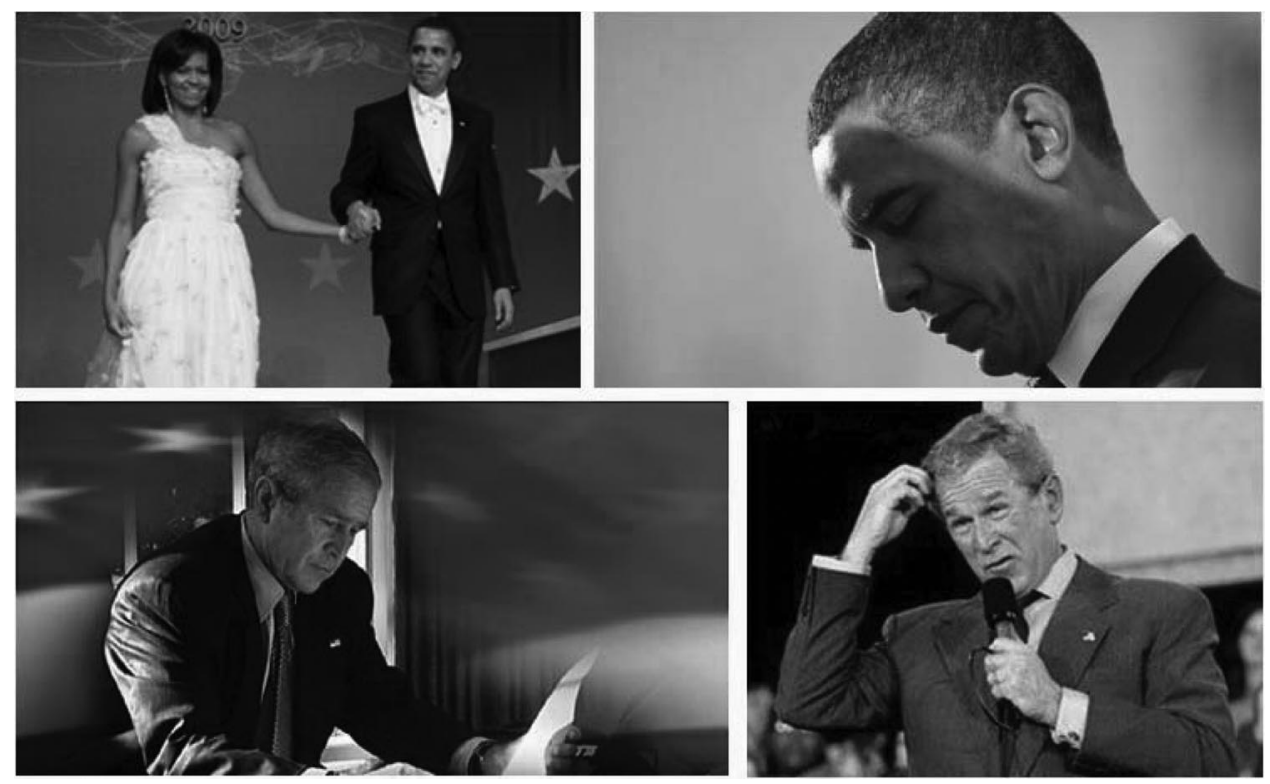

Figure 1. Example target images clockwise from top left: Obama: CNN.com (Warmth $=6.83$; Competence $=5.50)$; Obama: FOX.com (Warmth $=1.67$; Competence $=1.67)$; Bush: Huffington Post (Warmth $=1.33$; Competence $=1.00$ ); Bush: FOX.com $($ Warmth $=5.83$; Competence $=6.67)$.

mains. Naïve coders have also been shown to accurately code for affect and personality, showing adequate levels of interrater reliability (Waldinger, Schulz, Hauser, Allen, \& Crowell, 2004).

\section{Factor Analysis}

Interrater reliability was calculated for the four factors using the intraclass correlation coefficient (ICC; Shrout \& Fleiss, 1979), with naïve coders treated as random effects. This statistic assesses the degree of nonindependence among a set of observations, and is ideal for designs where multiple coders rate multiple targets, accounting for the proportion of total variance between raters (Cohen, Cohen, West, \& Aiken, 2003). Interrater reliability was satisfactory (competent ICC $=.65$; dominant ICC $=.69$; trustworthy ICC $=.56$; likable ICC $=.67$ ), and warmth and competence evaluations were thus averaged across coders. To confirm our targets were evaluated upon the two distinct dimensions of warmth and competence, we conducted confirmatory factor analyses. As expected, dominance and competence loaded highly on one factor, while trustworthiness and likability loaded highly on the other. A two-factor model fit the data significantly better than a singlefactor model, $\Delta \chi^{2}(1)=235, p<.001$, resulting in a good fit for the data, $\chi^{2}(1)=7.1, p=.008$, comparative fit index $=.995$, root mean square error of approximation $=.115$, normed fit index $=$ .995 , goodness of fit index $=.992$, incremental fit index $(\mathrm{IFI})=.995$. Ratings were thus averaged to create separate warmth and competence factors, upon which further analyses were conducted.

\section{Results}

We hypothesized that media outlets would portray political figures sharing their political leanings more positively than targets that did not, and specifically along the dimensions of competence and warmth. Our sample included roughly equal numbers of images of Obama and Bush, and we were not interested in contrasting different outlets, but rather assessing whether all outlets depicted targets sharing their affiliation as more warm and competent. Therefore, target evaluations from outlets sharing political orientation with media outlets (e.g., own-orientation) were compared to evalua- 
tions from media outlets that did not (e.g., otherorientation).

Bootstrap samples were then used to estimate whether own- or other-orientation predicted warmth and competence. Bootstrapping is a statistical method for estimating the sampling distribution of an estimator. This method is superior to more commonly utilized $t$ - and $F$ tests as no assumptions are made regarding the distribution of the data, and thus free from normality assumptions (Efron \& Tibshirani, 1993; Mooney \& Duval, 1993; Stine, 1989). Thus, a constrained nonlinear regression module was used to estimate coefficients from 1,000 bootstrap estimates, producing bias-corrected confidence intervals (CIs). Tests of significance are presented utilizing 95\% CIs, as CIs are superior to $p$ values in representing the potential for replication, and are considered significant if the intervals between the two values (e.g., 95\% CI $[-.150,-.100])$ do not include zero (Cumming, 2008). ${ }^{2}$

The results supported both our hypotheses, as images portrayed by media outlets of targets sharing their political orientation (mean $[M]=5.35$, standard deviation $[S D]=1.29)$ were rated as significantly more competent than other-orientation targets $(M=5.12$, $S D=1.28), 95 \%$ CI $[-.070,-.010]$. Additionally, own-orientation targets $(M=5.02$, $S D=1.29$ ) were rated as appearing reliably warmer than other-orientation targets $(M=4.70, S D=1.17), 95 \%$ CI $[-.090$, $-.030]$.

\section{Discussion}

This study sought to examine whether images presented in media outlets would vary predictably in competence and warmth. The results support this possibility and our predictions: targets sharing political orientation with media outlets were presented as more warm and competent than targets of an opposing political orientation. Images can increase the memorability of a news article (Katz et al., 1977), and as these qualities are considered universally important for leadership (Rule et al., 2010), the presentation of images that vary along warmth and competence can importantly influence the impressions that readers form about political figures (McCombs \& Shaw, 1972).

It is important to note that our sample was collected solely from images accompanying stories published during the presidential term. This was done purposefully in order to control for media exposure prior to a target's election, which may vary depending upon the strategy and funding of a particular campaign. However, given the broad impact of a president on the foreign and domestic policy of the subsequent four years, it might be particularly valuable to influence voters during electoral contests. An important extension of this research would be utilizing the current methodology to explore whether the warmth and competence of images increasingly varies between media outlets during periods sensitive to impression formation prior to electoral campaigns. The current work is useful and important in providing an objective measure to assess the ideology of a media outlet in such a situation, or in assessing a new website whose leanings are unknown. This method may be additionally useful in comparing the tone of the text of a news article compared to accompanying images or video.

One limitation of the present study is the categorization of media outlets as liberal- or conservative-leaning. Indeed, the true liberalism or conservatism of a media outlet varies in a wide, continuous spectrum, and is not as simplistic as our current dichotomization. For instance, different content within a single media outlet may vary drastically in the liberalism or conservatism of their perspectives. The classifications of liberal and conservative themselves are difficult, as one outlet may be more liberal/conservative regarding abortion while another is more liberal/conservative regarding gun laws (D'Alessio \& Allen, 2000). Additionally, here we have statistically assumed that, for example, CNN.com and MSNBC .com are equally liberal in content, when in reality this is unlikely to be the case. Future analyses might overcome these difficulties by treating liberalism and conservatism dimensions as continuous rather than categorical variables. However, the broad categorizations we make in the current research are supported by previous research (Coe et al., 2008; Iyengar \& Hahn, 2009), and continuous measures would only increase the statistical power of any analysis comparing bias in media images (Brauer,

\footnotetext{
${ }^{2}$ For a more in-depth explanation of confidence intervals, see Cohen, Cohen, West, and Aiken (2003).
} 
2002). Thus, we consider the current results a conservative test of our hypothesis.

The present research specifically targeted online news outlets in order to capitalize on the abundance of static images. Therefore, our results are limited in that we can only conclude biases exist in this particular medium. Whether they are present in other formats is unknown. A particularly important area to examine may be that of video (Graber, 1989, 1996), given the immense amount of information that can be conveyed in a short period of time through this format. We suspect that examination of other media may find results similar to those reflected in the current work.

Finally, as readers increasingly seek their news from online media outlets, we believe the present research is an important step in determining how the media may influence audiences in this relatively recent format. The extent of this influence remains undetermined. It is important for future research to examine the extent to which the consumption of media, ideologically congruent or incongruent with a reader's views, influences the reader's behavior and attitudes regarding political evaluations. How a target is portrayed influences subsequent evaluations in a political arena (Antonakis \& Dalgas, 2009; Caruso et al., 2009; Funk, 1997; Poutvaara et al., 2009; Rule et al., 2010; Todorov et al., 2005), and it is important to assess what impact such portrayals can have upon audience behavior.

\section{References}

Antonakis, J., \& Dalgas, O. (2009). Predicting elections: Child's play! Science, 323, 1183, 2009. doi: 10.1126/science. 1167748

Brauer, M. (2002). L'analyse des variables indépendantes continues et catégorielles: Alternatives à la dichotomisation. L'Année Psychologique, 102, 449-484. doi:10.3406/psy.2002.29602

Brubaker, J. (2010). Internet and television are not substitutes for seeking political information. Communication Research Reports, 27, 298-309. doi: 10.1080/08824096.2010.518906

Caruso, E. M., Mead, N. L., \& Balcetis, E. (2009). Political partisanship influences perception of biracial candidates' skin tone. PNAS, Proceedings of the National Academy of Sciences of the United States of America, 106, 20168-20173. doi: 10.1073/pnas.0905362106

Coe, K., Tewksbury, D., Bond, B. J., Drogos, K. L., Porter, R. W., Yahn, A., \& Zhang, Y. (2008).
Hostile news: Partisan use and perceptions of cable news programming. Journal of Communication, 58, 201-219. doi:10.1111/j.1460-2466 .2008.00381.x

Cohen, J., Cohen, P., West, S. G., \& Aiken, L. S. (2003). Applied multiple regression/correlation analysis for the behavioral sciences (3rd Ed.). Mahwah, NJ: Lawrence Erlbaum Associates Publishers.

Coleman, R. (2006). The effects of visuals on ethical reasoning: What's a photograph worth to journalists making moral decisions? Journalism and Mass Communication Quarterly, 83, 835-850.

Craig, R. (1999). Fact, public opinion and persuasion: The rise of the visual in journalism and advertising. In B. Brennen \& H. Hardt (Eds.), Picturing the past: Media, history and photography (pp. 36-59). Urbana, IL: University of Illinois Press.

Cumming, G. (2008). Replication and p intervals. Perspectives on Psychological Science, 3, 286300.

D’Alessio, D., \& Allen, M. (2000). Media bias in presidential elections: A meta-analysis. Journal of Communication, 50, 133-156. doi:10.1111/j.14602466.2000.tb02866.x

Efron, B., \& Tibshirani, R. (1993). An introduction to the bootstrap. New York, NY: Chapman \& Hall.

Funk, C. L. (1997). Implications of political expertise in candidate trait evaluations. Political Research Quarterly, 50, 675-697.

Graber, D. (1989). Content and meaning. What's it all about? American Behavioral Scientist, 33, 144152. doi: $10.1177 / 0002764289033002004$

Graber, D. (1996). Say it with pictures. The Annals of the American Academy of Political and Social Science, 546, 85-96. doi:10.1177/ 0002716296546001008

Hoffman, L. H. (2006). Is internet content different after all? A content analysis of mobilizing information in online and print newspapers. Journalism and Mass Communication Quarterly, 83, 58-76.

Iyengar, S., \& Hahn, K. S. (2009). Red media, blue media: Evidence of ideological selectivity in media use. Journal of Communication, 59, 19-39. doi:10.1111/j.1460-2466.2008.01402.x

Iyengar, S., \& Kinder, D. R. (1987). News that matters: Television and American opinion. Chicago, IL: University of Chicago Press.

Johnson, T. J., Kaye, B. K., Bichard, S. L., \& Wong, W. J. (2007). Every blog has its day: Politically interested internet users' perceptions of blog credibility. Journal of Computer-Mediated Communication, 13, 100-122. doi:10.1111/j.1083-6101 .2007.00388.x

Katz, E., Adoni, H., \& Parness, P. (1977). Remembering the news: What pictures add to recall. Journalism Quarterly, 54, 231-239. 
Kaye, B. K., \& Johnson, T. J. (2002). Online and in the know: Uses and gratifications of the Web for political information. Journal of Broadcasting \& Electronic Media, 46, 54-71. doi:10.1207/ s15506878jobem4601_4

Lee, J. K. (2007). The effect of the internet on homogeneity of the media agenda: A test of the fragmentation thesis. Journalism and Mass Communication Quarterly, 84, 745-760.

McCombs, M. E., \& Shaw, D. L. (1972). The agenda-setting function of mass media. Public Opinion Quarterly, 36, 176-187.

Messaris, P., \& Abraham, L. (2003). The role of images in framing news stories. In S. D. Reese, O. H. Gandy, \& E. August (Eds.), Framing public life: Perspectives on media and our understanding of the social (pp. 215-226). Mahwah, NJ: Lawrence Erlbaum.

Mooney, C. Z., \& Duval, R. D. (1993). Bootstrapping: A non-parametric approach to statistical inference. Newbury Park, CA: Sage.

Pew Research Center. (2009, October 29). Fox news viewed as most ideological network. Retrieved from http://people-press.org/2009/10/29/foxnews-viewed-as-most-ideological-network/

Pfau, M., Haigh, M. M., Shannon, T., Tones, T., Mercurio, D., Williams, R., ... Melendez, J. (2008). The influence of television news depictions of the images of war on viewers. Journal of Broadcasting and Electronic Media, 52, 303-322. doi:10.1080/08838150801992128

Poutvaara, P., Jordahl, H., \& Berggren, N. (2009). Faces of politicians: Babyfacedness predicts inferred competence but not electoral success. Journal of Experimental Social Psychology, 45, 1132 1135. doi:10.1016/j.jesp.2009.06.007

Purcell, K., Rainie, L., Mitchell, A., Rosenstiel, T., \& Olmstead, K. (2010, March 1). Understanding the participatory news consumer. Washington, DC: Pew Research Center. Retrieved from http:// www.pewinternet.org/reports/

Rule, N. O., Ambady, N., Adams, R. B., \& Macrae, C. N. (2008). Accuracy and awareness in the perception and categorization of male sexual orientation. Journal of Personality and Social Psychology, 95, 1019-1028. doi:10.1037/a0013194

Rule, N. O., Ambady, N., Adams, R. B., Ozono, H., Nakashima, S., Yoshikawa, S., \& Watabe, M. (2010). Polling the face: Prediction and consensus across cultures. Journal of Personality and Social Psychology, 98, 1-15. doi:10.1037/a0017673

Rule, N. O., \& Ambady, N. (2008). The face of success: Inferences from chief executive officers' appearance predict company profits. Psychological Science, 19, 109-111. doi:10.1111/j.14679280.2008.02054.x
Rule, N. O., \& Ambady, N. (2010). Democrats and Republicans can be differentiated from their faces. PloS one, 5, e8733. doi:10.1371/journal.pone.0008733

Sargent, S. L. (2007). Image effects on selective exposure to computer-mediated news stories. Computers in Human Behavior, 23, 705-726. doi: 10.1016/j.chb.2004.11.005

Scheufele, D. A., \& Tewksbury, D. (2007). Framing, agenda setting, and priming: The evolution of three media effects models. Journal of Communication, 57, 9-20.

Schulz, M. S., \& Waldinger, R. J. (2005). The value of pooling "naive" expertise: Comment. American Psychologist, 60, 656-657. doi:10.1037/0003066X.60.6.656

Sell, A., Cosmides, L., Tooby, J., Sznycer, D., von Reuden, C., \& Gurven, M. (2009). Human adaptations for the visual assessment of strength and fighting ability from the body and face. Proceedings Biological Sciences/ The Royal Society, 276, 575-584. doi:10.1098/rspb.2008.1177

Shrout, P. E., \& Fleiss, J. L. (1979). Intraclass correlations: Uses in assessing rater reliability. Psychological Bulletin, 86, 420-428. doi:10.1037/ 0033-2909.86.2.420

Stine, R. (1989). An introduction to bootstrap methods. Sociological Methods \& Research, 18, 243291. doi:10.1177/0049124189018002003

Todorov, A., Mandisodza, A. N., Goren, A., \& Hall, C. C. (2005). Inferences of competence from faces predict election outcomes. Science, 308, 16231626. doi:10.1126/science. 1110589

Waldinger, R. J., Schulz, M. S., Hauser, S. T., Allen, J. P., \& Crowell, J. A. (2004). Reading others' emotions: The role of intuitive judgments in predicting marital satisfaction, quality, and stability. Journal of Family Psychology, 18, 58-71. doi: 10.1037/0893-3200.18.1.58

Walma van der Molen, J. H., \& Klijn, M. E. (2004). Recall of television versus print news: Retesting the semantic overlap hypothesis. Journal of Broadcasting \& Electronic Media, 48, 89-107. doi:10.1207/s15506878jobem4801_5

Weaver, D. H. (1981). Media agenda setting in a presidential election: Issues, images, and interest. New York: Praegar.

Weaver, D. H. (1996). What voters learn from media. The Annals of the American Academy of Political and Social Science, 546, 34-47. doi:10.1177/ 0002716296546001004

Zillmann, D., Knobloch, S., \& Yu, H. (2001). Effects of photographs on selective reading of news reports. Media Psychology, 3, 301-324. doi: 10.1207/S1532785XMEP0304_01

Received August 1, 2011 Revision received September 13, 2011 Accepted October 31, 2011 